\title{
Effect of oral low dose pregabalin on succinylcholine induced fasciculations and myalgia -A prospective randomized double blind placebo-controlled study
}

\author{
Rashmi H D ${ }^{1}$, Hanumanthappa V. Airani ${ }^{2, *}$ \\ ${ }^{\mathbf{1}}$ Assistant Professor, ${ }^{\mathbf{2}}$ Associate Professor, Dept. of Anaesthesia, Hassan Institute of Medical Sciences, Hassan, Karnataka, India
}

*Corresponding Author:

Email: sridharairani@gmail.com

Received: $1^{\text {st }}$ March, 2018

Accepted: $27^{\text {th }}$ April, 2018

\begin{abstract}
Introduction: Among the depolarizing muscle relaxants, Succinylcholine is the widely used depolarizing agent until today in anaesthesia practice. Side effects like hyperkalemia, fasciculations, myalgia, increased intracranial pressure and intraocular pressure are common with the use of this drug. Pretreatment with various drugs have been proven to lessen these side effects. In our study, low dose of oral pregabalin was used as a premedication to assess its effects on the incidence and severity of fasciculations and postoperative myalgia caused by Succinylcholine administration.

Materials and Methods: 60 patients of either gender undergoing elective ENT surgeries under general anaesthesia were randomly allocated to two groups of 30 each. Patients in Group PG (pregabalin group) received $75 \mathrm{mg}$ of pregabalin orally $1 \mathrm{~h}$ prior to surgery and patients in Group CG (control group) received matching placebo. Fasciculations and myalgia grading was done by a blinded observer. Haemodynamic variables were measured at regular intervals.

Results: Both groups were comparable in regard to Demographic data ( $p>0.05)$. We didn't find any significant difference in the fasciculations incidence $(p=0.702)$ and myalgia incidence $(p=0.081)$ between the two groups. But the severity of fasciculations is statistically significant between the groups $(<0.001)$. After $24 \mathrm{~h}$ of surgery, severity of myalgia is mild $(86.9 \%)$ in PG group when compared to $\mathrm{CG}$ group which was of moderate variety $(80.7 \%)(P<0.001)$.

Conclusion: Low dose oral pregabalin- $75 \mathrm{mg}$ decreases the severity of succinylcholine-induced fasciculations and myalgia. There is not much effect on the incidence of fasciculations and myalgia in patients undergoing elective ENT surgeries.
\end{abstract}

Keywords: Succinylcholine, Low dose Pregabalin, Fasciculations, Myalgia.

\section{Introduction}

Succinylcholine induced fasciculations is very common in patients undergoing surgeries under general anaesthesia. Postoperative myalgia resulting from this is very annoying to the patients. Many drugs like non depolarizing agents, ketorolac, diclofenac have been used in the past to prevent this side effect. Pregabalin has been recently used to prevent this side effect. Pregabalin is a structural analog of the neurotransmitter $\gamma$-aminobutyric acid (GABA). It is an $\alpha_{2} \delta$ calcium channel antagonist that inhibits presynaptic neurotransmitter release like glutamate and substance $P$. Only fewer studies are available to know the effect of pregabalin on succinylcholine induced fasciculations and myalgia. In this study, we studied the effect of oral low dose pregabalin on the incidence and severity of fasciculations and postoperative myalgia caused by administration of succinylcholine

\section{Materials and Methods}

After obtaining clearance from institutional ethical committee and informed consent from all the patients, this study was conducted in a prospective, double blind, placebo contolled manner in our institution over a period of 6 months.

Sixty adult patients of either gender, belonging to ASA class I and II aged between 18 and 60years, scheduled for elective ear, nose and throat (ENT) surgeries under general anesthesia were enrolled for the study. Patients with known hypersensitivity to pregabalin and subjects who had received sedatives and analgesics other than those determined by the study protocol, patients with liver and kidney diseases, were excluded from the study. Also patients in whom succinylcholine was contraindicated like burns patient, chronic kidney disease patients were excluded from the study.

The patients were allocated to either of the two groups- pregabalin group (Group PG) and control group (Group CG) by computer generated randomization technique.

Patients in Group PG received pregabalin $75 \mathrm{mg}$ orally with sips of water, $1 \mathrm{~h}$ before the induction of anaesthesia.

Patients in Group CG received matching placebo orally with sips of water, $1 \mathrm{~h}$ before the induction of anaesthesia

After shifting the patient to operation room, intravenous cannulation was done and Ringer Lactate infusion was started. Baseline values of heart rate (HR), noninvasive blood pressure (NIBP), and pulse oximetry $(\mathrm{SpO} 2)$ was noted. Electrocardiogram (ECG) and all vital parameters were monitord throughout the study. Premedication was done with Inj. Ranitidine $50 \mathrm{mg}$ IV, Inj. Ondansetron $4 \mathrm{mg}$ IV and Inj. Butorphanol $1 \mathrm{mg}$ IV.

Induction of Anaesthesia was done with Inj. Thiopentone $5 \mathrm{mg} / \mathrm{kg}$ Intravenously (IV). Loss of 
eyelash reflex was considered as the endpoint of induction. At this point, Inj. succinylcholine $2 \mathrm{mg} / \mathrm{kg}$ IV was administered. Soon after the administration of succinylcholine, fasciculations were observed. Fasciculation grading ${ }^{1}$ is as follows: nil (absent), mild (fine fasciculation of the eyes, face, neck, or fingers without movements of the limbs), moderate (obvious muscle twitching at more than one sites or movement of limb), or severe (vigorous, sustained, and widespread fasciculations) by a blinded observer.

After one minute of administration of succinylcholine, endotracheal intubation was performed with appropriate size endotracheal tube. Bilateral airentry was confirmed. Maintenance of anaesthesia was done with a mixture of nitrous oxide and oxygen (2:1), halothane $0.5 \%$ and intermittent doses of vecuronium bromide. At the end of procedure, neuromuscular blockade was reversed by neostigmine and glycopyrolate.

Myalgia was assessed in the postoperative period, $24 \mathrm{~h}$ after the surgery by a blinded observer in all patients.

Grading of myalgia ${ }^{1}$ was done according to below mentioned scale.

Nil (absence of pain), mild (muscle stiffness or pain on specific questioning in nape of neck, shoulders, and lower chest on deep breathing), moderate (muscle stiffness and pain complained of by the patient spontaneously requesting analgesia), or severe (incapacitating generalized muscle stiffness or pain).

Surgical pain and myalgia is differentiated by the site and type of pain. Surgical pain is more confined to the site of surgery, whereas myalgia is generalized pain not confined to specific site. Also surgical pain is more of visceral pain whereas myalgia is somatic type of pain.

The postoperative sedation level was assessed by the Ramsay sedation score which consists of the following six grades: anxious (1), cooperative and tranquil (2), responding to commands only (3), brisk response to light glabellar tap (4), sluggish response to light glabellar tap (5), and no response to light glabellar tap (6).

We calculated the sample size of 60 (30 subject in each group) for our study based on the pilot study, with $96 \%$ incidence of fasciculation. We calculated that 30 subjects were required per group based on the power of $80 \%$ and type I error of 5\%. Statistical analysis was performed using the SPSS 21.0 software. The demographic data and sedation scoring were analyzed by using Student $t$-test whereas the incidence and severity of fasciculation and myalgia were analyzed using Fisher's exact test. A p value of $<0.05$ was considered statistically significant.

\section{Results}

The demographic data of patients of the two groups were comparable Table 1.

There was no significant differences in respect to age, body weight, gender, type of surgery and duration of surgery.

The incidence and different grades of muscle fasciculations observed in the study are shown in the Table 2.

The overall incidence of muscle fasciculations was $83.3 \%$ in PG group as compared to $93.3 \%$ in CG group. There was no stastistically significant difference in the incidence of fasciculations $(\mathrm{p}=0.702)$ between the two groups. However in regard to the severity of muscle fasciculations, there was significant difference. 22 (88\%) patients in PG group had mild fasciculations whereas only $3(10.7 \%)$ patients in CG group had mild fasciculations which was stastically significant $(\mathrm{p}<$ $0.001) .2(7.2 \%)$ patients in group CG had severe fasiculations while none of the patient in group PG had severe fasciculations.

The incidence and different grades of postoperative myalgia observed in the study are shown in the Table 3

The incidence of myalgia was $76.6 \%$ in PG group while it was $86.6 \%$ in CG group which was not of any statistical significance. $(\mathrm{p}=0.081)$

In PG group, $20(86.9 \%)$ patients developed mild degree of myalgia and $3(13.04 \%)$ patients developed moderate degree of myalga. In CG group $4(15.38 \%)$ patients developed mild degree of myalgia and $21(80.76 \%)$ patients developed moderate degree of myalgia. Henceforth, there was a statistically significant difference $(p<0.001)$ in regard to severity of myalgia in the postoperative period in between the groups.

Haemodynamically stability was maintained in patients of both the groups.

There was no statistically significant difference between two groups in the haemodynamic parameters like heart rate and mean arterial blood pressure (Graph 1).Ramsay sedation scoring showed no significant difference in between the two groups at any point of time ( $p>0.05)$ as shown in Table 4.

Table 1: Distribution of patients based on age, sex, body weight, type of surgery and duration of surgery

\begin{tabular}{|l|c|c|c|}
\hline & Group- PG (n=30) & Group- CG $(\mathbf{n = 3 0})$ & P-Value \\
\hline Mean Age \pm SD (Yrs) & $38.62 \pm 8.16$ & $40.12 \pm 9.26$ & 0.561 \\
\hline Mean Body Weight \pm SD (Kgs) & $52.28 \pm 7.24$ & $53.18 \pm 6.96$ & 0.502 \\
\hline Sex Ratio (M:F) & $17: 13$ & $14: 16$ & 0.544 \\
\hline $\begin{array}{l}\text { Type of surgery: } \\
\text { Ear/Nose/Throat }\end{array}$ & $3 / 16 / 11$ & $2 / 18 / 10$ & 0.342 \\
\hline Duration of surgery (Mins) & $118.72 \pm 12.14$ & $114.53 \pm 16.18$ & 0.621 \\
\hline
\end{tabular}


Table 2: Distribution of patients based on incidence and severity of fasciculations between two groups

\begin{tabular}{|c|c|c|c|}
\hline Incidence of Fasciculations & Group- PG $(n=30)$ & Group- CG $(n=30)$ & P- Value \\
\hline Yes & $25(83.3)$ & $28(93.3)$ & \multirow[t]{2}{*}{0.702} \\
\hline No & $5(16.7)$ & $2(6.7)$ & \\
\hline \multicolumn{4}{|l|}{ Severity of Fasciculations } \\
\hline Mild & $22(88)$ & $3(10.7)$ & \multirow{3}{*}{$<0.001 *$} \\
\hline Moderate & $3(12)$ & $23(82)$ & \\
\hline Severe & 0 & $2(7.2)$ & \\
\hline
\end{tabular}

Figure in the parenthesis indicate percentage. *Statistically significant

Table 3: Distribution of patients based on incidence and severity of myalgia between two groups

\begin{tabular}{|l|c|c|c|}
\hline Incidence of Myalgia & Group- PG $(\mathbf{n = 3 0})$ & Group- CG $(\mathbf{n}=30)$ & \multirow{2}{*}{0.081} \\
\hline Yes & $23(76.6)$ & $26(86.6)$ & \\
\hline No & $7(23.3)$ & $4(13.3)$ & \multirow{2}{*}{$<0.001^{*}$} \\
\hline Severity of Myalgia & \multicolumn{3}{|l|}{} \\
\hline Mild & $20(86.9)$ & $4(15.38)$ & \\
\hline Moderate & $3(13.04)$ & $21(80.76)$ & \\
\hline Severe & 0 & $1(3.84)$ & \\
\hline
\end{tabular}

Figure in the parenthesis indicate percentage. *Statistically significant

Table 4: Ramsay sedation scoring between the two groups

\begin{tabular}{|l|c|c|}
\hline Score & Group PG $(\mathbf{n}=30)$ & Group CG $(\mathbf{n}=30)$ \\
\hline 1 & $28(93.3)$ & $27(90)$ \\
\hline 2 & $2(6.7)$ & $3(10)$ \\
\hline 3 & 0 & 0 \\
\hline 4 & 0 & 0 \\
\hline 5 & 0 & 0 \\
\hline 6 & 0 & 0 \\
\hline
\end{tabular}

Figure in the parenthesis indicate percentage

Graph 1: Mean Heart rate and Mean arterial pressure at different intervals between the two groups

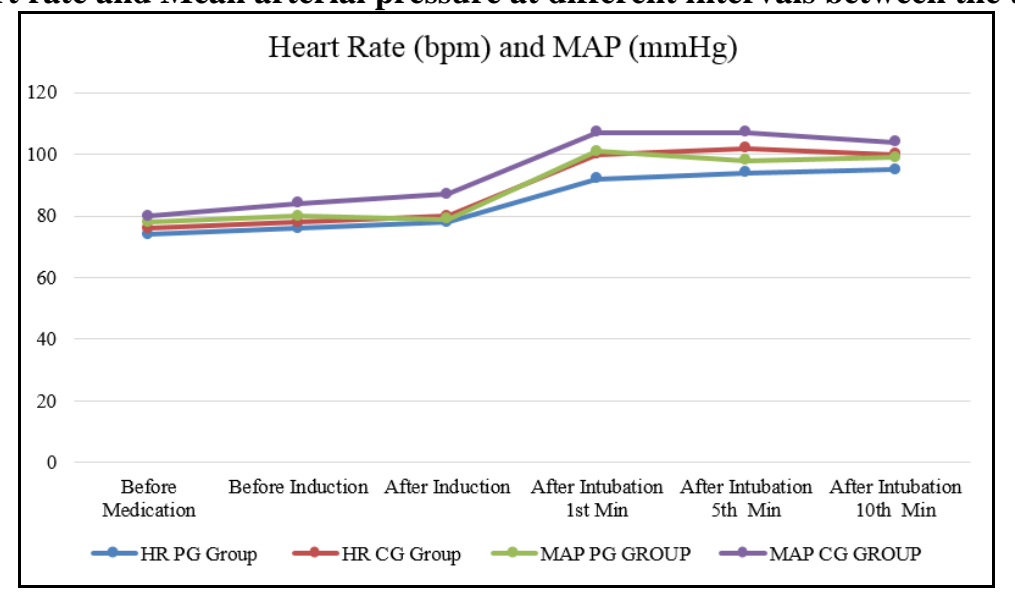

\section{Discussion}

Succinylcholine is the most common depolarizing muscle relaxant used in anaesthesia practice as it produces profound neuromuscular blockade and excellent intubating conditions. But it has many side effects like fasciculations, postoperative myalgia, hyperkalemia, increased intracranial pressure etc.

The incidence of postoperative myalgia, which is more in first postoperative day was reported to be ranging from $41 \%$ to $92 \%{ }^{2}$ The exact pathophysiology of the occurrence of myalgia is unknown. Various theories and mechanisms have been proposed which includes increase in the myoplasmic calcium concentrations, release of free fatty acids, free radicals and membrane phospholipids degradation. ${ }^{3-5}$

Various pretreatment modalities have been tried to combat these side effects like fasciculations and myalgia. Pretreatment with non-depolarizing agents like d-tubocurare, ${ }^{6}$ and pancuronium, ${ }^{7}$ vecuronium, ${ }^{8}$ rocuronium, ${ }^{9}$ atracurium ${ }^{10}$ are commonly used. NSAIDs 
like ketorolac $^{11}$ diclofenac sodium, ${ }^{12}$ sedatives like diazepam,,$^{13}$ are also used. Magnesium sulfate, ${ }^{14}$ small dose of succinylcholine (self-taming $)^{10}$ have also been tried. Nowadays pretreatment with pregabalin ${ }^{15,16}$ and gabapentin ${ }^{16,17}$ has been done to combat this side effect.

Pregabalin is structurally related to the antiepileptic drug gabapentin and the site of action of both drugs is similar, the alpha 2-delta subunit of voltage-gated calcium channels. It reduces the presynaptic release of several neurotransmitters, by binding to alpha2-delta subunits. While its mechanism of action is not completely understood, the analgesic, anticonvulsant, and anxiolytic actions of pregabalin are thought to result from decreasing central nervous system (CNS) concentrations of excitatory neurotransmitters including glutamate and substance P. ${ }^{18,19}$

Srivastava et $\mathrm{al}^{15}$ conducted a study using oral pregabalin $150 \mathrm{mg}$ to know its effects on the succinylcholine induced fasciculations and myalgia. Oral pregabalin-150 mg was given 1 hour before induction of anaesthesia in patients posted for elective spine surgery. Fasciculations and myalgia grading was done. They concluded that $150 \mathrm{mg}$ of oral pregabalin decreased the severity of muscle fasciculations without an effect on its incidence which is similar to our study. It also decreased the incidence and severity of myalgia and postoperative fentanyl consumption in elective spine surgery

Pandey C.K. Karna, S.T et al. ${ }^{16}$ had done a study comparing pregabalin, gabapentin and diclofenac sodium for the prevention of succinylcholine induced myalgia. They demonstrated that the incidence of myalgia is similar in all 3 groups. But the severity of postoperative myalgia and fentanyl consumption were less in pregablin and gabapentin group when compared to diclofenac group. This observation is similar to our study wherein severity of myalgia is less in pregabalin group.

In a study done by CK Pandey, M Tripathi et al, ${ }^{17}$ $600 \mathrm{mg}$ of oral gabapentin was given 2 hours prior to surgery. They concluded that prophylactic use of gabapentin significantly decreases the incidence and the severity of myalgia and decreases the fentanyl consumption significantly in the postoperative period. It didn't had effects on the incidence and severity of fasciculations.

In our study, we have used a low dose of oral pregabalin-75 $\mathrm{mg}$ to assess its effects on the incidence and severity fasciculations and myalgia after the administration of succinylcholine. We found that low dose of oral pregabalin significantly decreases the severity of fasciculations without any effect on the incidence of fasciculations. There is also a significant decrease in the severity of myalgia in the pregabalin group without any effect on the incidence of myalgia. Ramsay sedation scoring between the two groups didn't show significant difference. There was no to minimal sedation between the two groups. There was also no significance regarding haemodynamic variables.

\section{Conclusion}

We conclude that prophylactic use of low dose of oral pregabalin decreases the severity of succinylcholine induced fasciculations and myalgia without any effect on the incidence of both. Haemodynamic stability is maintained in both the groups.

\section{References}

1. Kahraman S, Ercan S, Aypar U, Erdem K. Effect of preoperative I.M. administration of diclofenac on suxamethonium-induced myalgia. Br J Anaesth. 1993;71:238-41.

2. Smith I, Ding Y, White PF. Muscle pain after outpatient laproscopy-Influence of propofol versus thiopental and enflurane. Anesth Analg. 1993;76:1181-4.

3. McLoughlin C, Elliott P, McCarthy G. Muscle pains and biochemical changes following suxamethonium administration after six pretreatment regimens. Anaesthesia. 1992;47:202-6.

4. Wong SF, Chung F. Succinylcholine-associated postoperative myalgia. Anaesthesia. 2000;55:144-52.

5. Allen DG. Skeletal muscle function: role of ionic changes in fatigue, damage and disease. Clin Exp Pharmacol Physiol. 2004;31:485-93.

6. Sosis M, Broad T, Larijani GE, Marr AT. Comparison of atracurium and d-tubocurarine for prevention of succinylcholine myalgia. Anesth Analg. 1987;66:657.

7. Brodsky JB, Brock-Utme JG, Samuels SI. Pancuronium pretreatment and post succinylcholine myalgias. Anesthesiology 1979;51:259-61.

8. Ferres C, Mirakhur R, Craig H, Browne E, Clarke R. Pretreatment with vecuronium as a prophylactic against post suxamethonium muscle pain: Comparison with other non depolarising neuromuscular blocking drugs. $\mathrm{Br} \mathrm{J}$ Anaesth. 1983;55:735-41.

9. Demers-Pelletier J, Drolet P, Girard M, Donati F. Comparison of rocuronium and d-tubocurarine for prevention of succinylcholine induced fasciculations and myalgia. Can J Anaesth. 1997;44:1144.

10. Hajimohamadi Fatemeh, Rahimi Mojgan. Comparison of Atracurium and "Mini-dose" Succinylcholine for Preventing Succinylcholine-induced Muscle Fasciculations: A Randomized, Double-Blind, Placebocontrolled Study. Acta Anaesthesiol Taiwan. 2010;48(1):28-32.

11. Leeson Payne C, Nicoll JM, Hobbs GJ. Use of ketorolac in the prevention of suxamethonium myalgia. $\mathrm{Br} \mathrm{J}$ Anaesth. 1994;73:788-90.

12. Kahraman S, Ercan S, Aypar U, Erdem K. Effect of preoperative I.M. administration of diclofenac on suxamethonium-induced myalgia. Br J Anaesth. 1993;71:238-41

13. Fahmy NR, Malek NS, Lappas DG. Diazepam prevents some adverse effects of succinylcholine. Clin Pharmacol Ther. 1979;26:395-8.

14. Mahendra Kumar, Nalin Talwar, Ritu Goyal, Usha Shukla, AK Sethi. Effect of magnesium sulfate with propofol induction of anesthesia on succinylcholineinduced fasciculations and myalgia. Journal of Anaesthesiology Clinical Pharmacology. 2012;28(1).

15. Vinit K Srivastava, Sanjay Agarwal, Vikrant K. Prophylactic use of pregabalin for prevention of 
succinylcholine-induced fasciculation and myalgia: A randomized, double-blinded, placebo-controlled study. Brazilian journal of anesthesiology. (English edition) 2014.

16. Pandey C.K, Karna, S. T, Tandon, M. Pandey. Compartive evaluation of prophylactic use of pregabalin, gabapentin and diclofenac sodium for prevention of succinylcholine -induced myalgia: A randomized, double -blinded study. J Postgrad Med. 2014;60(1):16-20.

17. Pandey C K, Tripathi M, Joshi G, Karna S T, Singh N, Singh P K. Prophylactic use of gabapentin for prevention of succinylcholine-induced fasciculation and myalgia: A randomized, double-blinded, placebo-controlled study. $J$ Postgrad Med. 2012;58:19-22.

18. Taylor CP, Angelotti T, Fauman E. Pharmacology and mechanism of action of pregabalin: the calcium channel alpha2-delta (alpha2-delta) subunit as a target for antiepileptic drug discovery. Epilepsy Res. 2007;73(2):137-50.

19. Chad S Boomershine. Pregabalin for the management of fibromyalgia syndrome. J Pain Res. 2010;3:81-88.

How to cite this article: Rashmi HD, Airani HV. Effect of oral low dose pregabalin on succinylcholine induced fasciculations and myalgia -A prospective randomized double blind placebo-controlled study. Indian J Clin Anaesth. 2018;5(3):368-372. 